\title{
Experience with treatment of road structure landslides by innovative methods of deep drainage
}

\author{
O. Mrvík ${ }^{1} \& \mathrm{~S}$. Bomont ${ }^{2}$ \\ ${ }^{1}$ Department of Geotechnics, Czech Technical University in Prague, \\ Czech Republic \\ ${ }^{2}$ TP.GEO, France
}

\begin{abstract}
During construction of infrastructure projects, emergency situations due to the presence of groundwater and slope instability occur very often. In addition, damage to existing roads or railways caused by groundwater or slope deformations do not represent any extraordinary situation. In such cases, the water should be taken from the ground in order to improve the properties of the soils and rocks. According to the consumption of energy, the methods of dewatering can be divided into gravity dewatering and dewatering with electricity. Traditionally used drainage techniques are proven methods. However, in certain geotechnical conditions, two innovative drainage systems, Siphon Drains and Electropneumatic Drains, can prove to have many advantages. In this paper, several applications of the innovative deep drainage systems are described. The paper introduces selected sites where groundwater lowering played a key role in the successful solution of slope stabilization and road remediation. The sites are located in France.
\end{abstract}

Keywords: road structures, landslide, groundwater, deep drainage, Siphon Drains, Electropneumatic Drains.

\section{Introduction}

Road structures, as roads, highways or railways, are very often endangered or even seriously damaged by different kinds of deformations of natural slopes or artificial excavations. The main trigger for such deformations lies in high groundwater levels within the affected area or just the subsoil of the road 
embankment. Therefore, groundwater lowering is primarily the most important measure in order to avoid the risk of slope movements, damage to the road structures and, secondarily, to protect the affected areas against repeated deformation and destruction.

Geotechnical designers responsible for the treatment of such problems should always recognize the main reasons for the situation, evaluate the geotechnical conditions of the site and look for the most effective solution. The decisionmaking process of a proper drainage system to drain and stabilize the affected site might be as follows.

Traditional methods of dewatering, such as drainage trenches, are usually limited by their maximal economical depth of 3-5 m. Deeper excavations would cause huge and non-economical earthworks and extra expenses for gravel backfilling. In the case of subhorizontal wells, considerable length of drilling, difficulties in reaching all aquifers and problems of site access can be considered as significant disadvantages. Alternatively, the innovative method of Siphon Drains ${ }^{\circledR}$, which allows dewatering up to $8-12 \mathrm{~m}$ beneath the surface without the need for electrical energy, can be adopted.

Deep drainage and groundwater lowering deeper than 10 meters today still represents a great deal of effort and implies a difficult technique. However, sometimes it is inevitable to reach deeper aquifers that might cause many serious problems in construction and to deal with groundwater lowering of tens of meters. Traditional techniques are very often badly fitted to achieve such requirements. Submersible pumps require a rather high minimum flow and frequent expensive maintenance. Well points efficiency is limited to a depth of 7 meters lower than the level of the vacuum pump. The innovative method of Electropneumatic Drains ${ }^{\circledR}$ has been developed to lower the water table up to 40-60 meters below ground level using pneumatic energy (compressed air).

The groundwater problem at the first three of four introduced sites was treated by Siphon Drains as a permanent energy-free solution. The last case study introduces an application of Electropneumatic Drainage as a permanent solution to an emergency problem that occurred soon after construction of a project of highest importance.

\section{Innovative methods of deep drainage}

\subsection{Siphon drains}

Small diameter $(10-30 \mathrm{~mm})$ suction siphon tubes are placed into vertical wells. The wells are spaced between 3-6 $\mathrm{m}$ and are sufficiently deep to provide required drawdown. The wells are dewatered using the siphon principle based on gravity drawdown up to depths of 8-12 m beneath the surface (Fig. 1).

The tubes are inserted into a permanent water filled reservoir at the base of each well with an outlet downstream at an outlet manhole, situated down slope. If the water level rises in the well, the flow in the tube is renewed and abstracts water out of the well. The flow continues until the water level in the well falls back to the reference level, providing that the flow rate in the siphon is sufficient to keep the siphon primed. As the water rises towards the top of the tube, the 

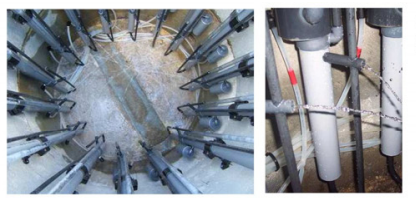

Outlet Manhole Equipped by Flushing Systems

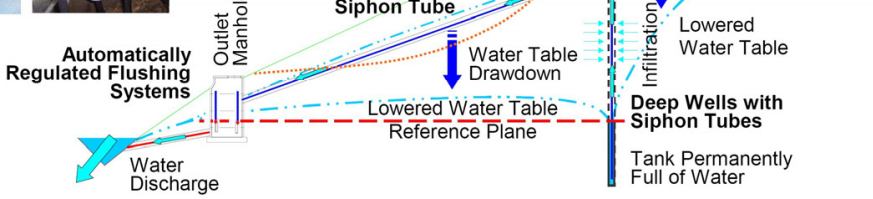

Figure 1: $\quad$ Basic principles of Siphon Drainage.
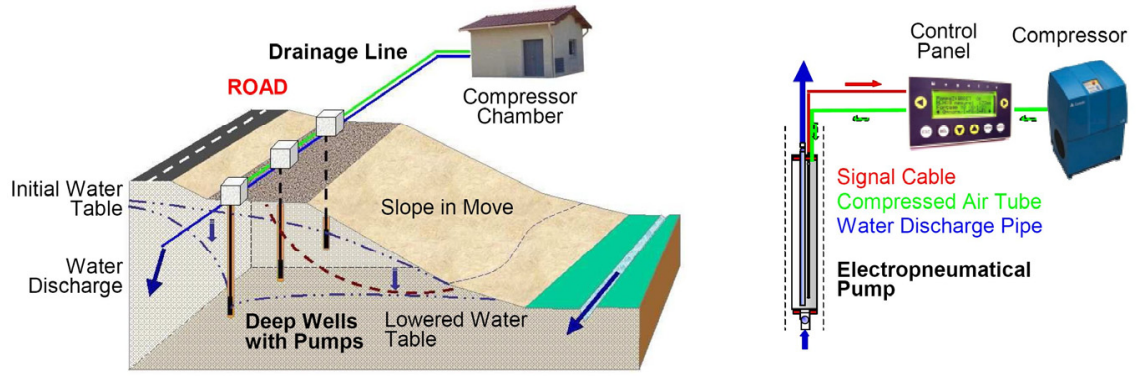

Figure 2: $\quad$ Arrangement of Electropneumatic Drainage.

pressure falls and may reach vacuum, causing the creation of bubbles. Without any additional measure, the bubbles might cause the flow to break. This is avoided by using the flushing system, which flushes bubbles out by turbulent flow and controls and regulates the flow so that the siphon always stays primed. The flushing system is an arrangement of PVC pipes and it is placed downstream in the outlet manhole at the end of each siphon tube.

The method is suitable for the geological environment of permeabilities less than $10^{-5} \mathrm{~m} / \mathrm{s}$ and groundwater inflows of $0.0-2.0-15.01 / \mathrm{min}$ per well (i.e. 0.0 $0.03-0.3 \mathrm{l} / \mathrm{s}$ per well). The main advantages are: the system is automatically continually in service, it is easily controlled, of high efficiency and can facilitate drawdowns of up to $12 \mathrm{~m}$, without the need for any additional energy.

\subsection{Electropneumatic Drains}

The drainage is designed by a network of vertical wells, manholes, ducting for cabling and pipes for water discharge and compressed air (Fig. 2). The wells are spaced between 3-6 $\mathrm{m}$ and are sufficiently deep to provide the required drawdown. The wells are equipped with a casing of $110 \mathrm{~mm}$ diameter and a gravel filter. Electropneumatic pumps are installed into the wells at a defined depth, connected to a compressor and the control panel and equipped with an intelligent sensor. When the groundwater rises in the wells, it fills the pumps and when it reaches the high level sensor, an electrical signal is transmitted to the control panel, including the relays and solenoids. The signal triggers the injection 
of compressed air into the pumping chamber to push water out onto the surface through an outlet tube. The pump filling and emptying is repeated until the required drawdown is reached.

The system manages groundwater lowering of up to $60 \mathrm{~m}$ under permeabilities of $1.10^{-5}-1.10^{-7} \mathrm{~m} / \mathrm{s}$ with groundwater inflows of $0.0-35.01 / \mathrm{min}$ per well (i.e. $0.0-0.6 \mathrm{l} / \mathrm{s}$ per well). The main advantages are: the system runs only under high groundwater level, the pumps contain no moving mechanical parts and both operation and maintenance expenses are saved.

\section{RD74 - Goncourt}

At this site, the affected section of the road is situated on a slope above a shallow valley with a river at the bottom (Fig. 3). The valley is filled mainly by soft sediments, such as clays. The bedrock is created by alternating marls and limestones. At the top of the slope, the limestones are exposed either by natural outcrops and cuttings made during construction of the road. The limestones are affected by karstic effects and by mechanical weathering. A complicated system of the groundwater of many aquifers confined mainly in cracks and voids is developed within the limestone formation. Infiltration of surface water was allowed. The water flow follows the slope so that the soft sediments in the lower parts of the valley were saturated. The water that occurred in the clays was very shallow, 0-5 $\mathrm{m}$ below surface. As the slope is being undercut by the river erosion, deformations in the saturated clays were initiated easily. These deformations were accompanied by gravity moves of limestone blocks in the upper part of the slope. Downstream movements of the limestone blocks caused deformations of the road. The affected area was $300 \mathrm{~m}$ in width and $150 \mathrm{~m}$ in length. The deepest deformations were expected to be $10 \mathrm{~m}$.

To eliminate the deformations and to avoid future road destructions, the water coming from the top of the slope had to be drained so that the shear properties of the clays in which sliding occurred would be improved. Predominantly, longterm permanent gravity drainage without the need for energy was required. Pumping of the water from deep wells situated at the top of the slope would have been possible, but very time consuming. Continual water flow of a huge amount was expected. Horizontal wells carried out from the bottom of the slope would have to be very long. Reaching all of the required aquifers would not be guaranteed by horizontal boreholes. A drainage trench situated below the top of the hill was taken into account. Such a trench would have to be very deep to attain the deepest aquifer. The earthworks and the gravel backfill of such an excavation would be extremely expensive. Moreover, it might be dangerous to cut the slope by a 5-10 m deep trench that could break the weak stability or suddenly bring a lot of groundwater from cracks to the slope. The system of Siphon Drains was selected as the most suitable and effective.

A single drainage line of 71 drains was situated in the slope as an artificial water barrier (Fig. 4). The purpose of the drainage was to take the incoming water out of the slope and to lower the water table permanently. A shallow trench of $1.2 \mathrm{~m}$ minimum depth in which to place all necessary ducting, as well 


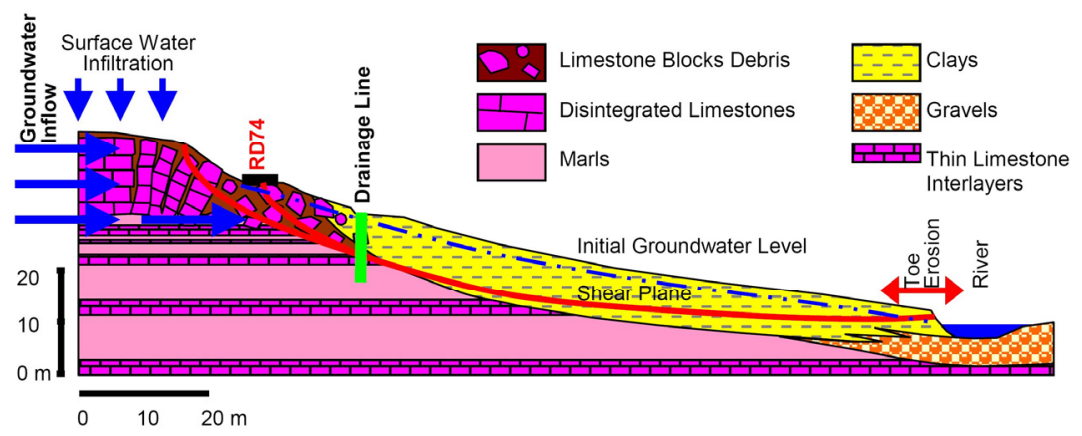

Figure 3: $\quad$ Cross-section of the affected slope at Goncourt.
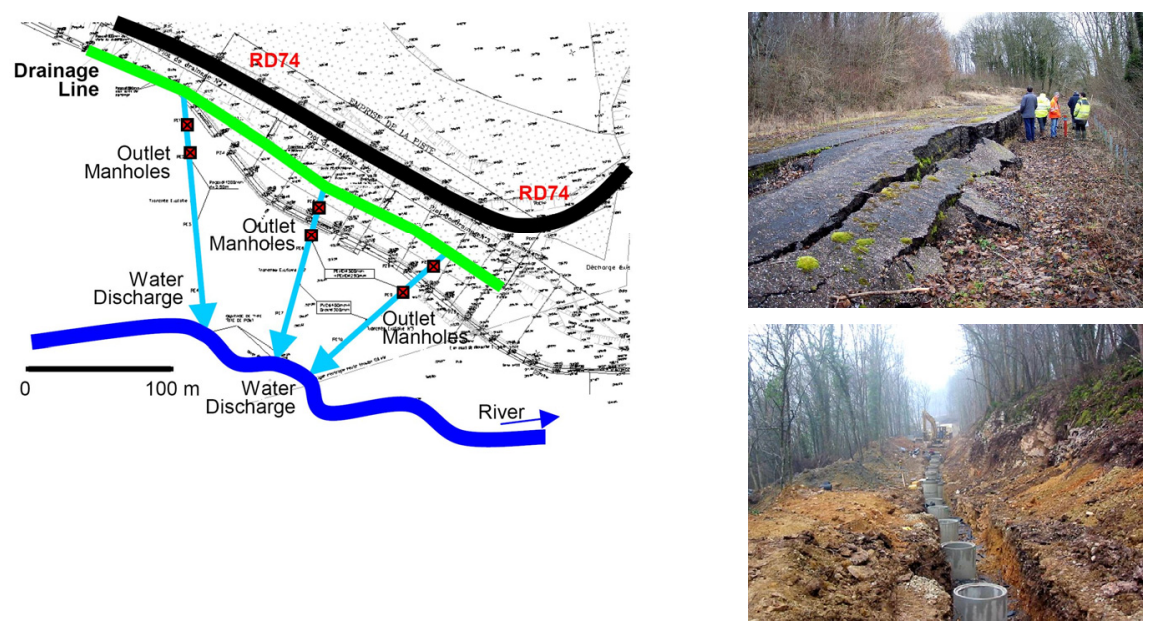

Figure 4: Scheme of the Siphon Drainage System at Goncourt.

as to protect the equipment of the Siphon Drainage technology against frost action and mechanical destruction, was excavated first. Protective drainage manholes made of concrete prefabricates $\varnothing 800 \mathrm{~mm}$ were placed at the position of each drain. The trench was partially backfilled by gravel and a perforated plastic duct was placed at the bottom to be used as a surface drain. The wells were drilled at $\varnothing 250 \mathrm{~mm}$ from the top of the manholes after backfilling the trench. The drains are $12.5 \mathrm{~m}$ deep and spaced at $5 \mathrm{~m}$. The wells were equipped as standard opened piezometers. A perforated plastic pipe $\varnothing 110 / 114 \mathrm{~mm}$ was inserted into the boreholes and the space between the borehole and the screen was filled with filtrating gravel of 2-4 mm. An Air-lift to clean the wells was applied.

The collected groundwater was directed through siphon pipes (one for each drain) in three evacuation lines. The water collected by the drains is sucked out of the wells by the natural siphon principle through $10 / 12 \mathrm{~mm}$ diameter plastic siphon pipes inserted into each well and pulled through the burned ducting pipes 
between neighbouring manholes to three crosspoint manholes and then to six downstream placed common outlet manholes. Flushing systems for each drain were installed in the outlet manholes. The siphon tubes were primed by water under pressure and the outlet endings of the siphon pipes were connected to relevant flushing systems. A system of continual groundwater monitoring by piezometers was established.

After the system was put in function, the groundwater level in each well was lowered to $8-11 \mathrm{~m}$ below the terrain. In the initial stages of the drainage function, the global water discharge reached $250 \mathrm{l} / \mathrm{min}$ (3.5 1/min per drain). The current overall values of the water flow through the system are around $70 \mathrm{l} / \mathrm{min}$ (1 $1 /$ min per well). As of 2010 , the system had already been in operation for seven years without any defects. Regular periodical maintenance of the drainage is carried out. No significant problems with the stability of the area occur anymore.

\section{RD95 - Aigueblanche}

On the national road RD95, for 3.680-3.800 km, considerable ground movements and problems with instability have been occurring for more than ten years. The instability was characterized by several active landslide zones developed on a steep slope in the altitudes between $700-850 \mathrm{~m}$ above sea level (Fig. 5). The rate of deformations varied from 10 to $70 \mathrm{~mm}$ per year and according to the inclinometry measurements, the depth of active shear planes varied between 6 and $14 \mathrm{~m}$ beneath the surface. The geological settings were designated as favourable for groundwater circulation and surface water infiltration. The ground is created by mixed rockmass and soils and it is composed of shales of variable degrees of weathering and clays. The initial piezometric levels were observed at a few levels between 1.5-3.0 m.

The results of a research study were that the sliding is too complex to stabilize the slope entirely by implementing mechanical barriers as pile walls or "Berlin" walls or some other method. The water table had been observed to be too high at the site. Geotechnical studies considered that the establishment of a drainage network with an $8 \mathrm{~m}$ depth efficiency should allow certain improvement of the safety factor, but still the drainage solution would not allow the complete stabilization of the slide. However, this solution was expected to slow down the movements and thereby reduce the deformations of the roadway. The gravity driven drainage system by means of Siphon Drains was chosen to achieve these goals.

Since the purpose of the drainage was just to reach a certain groundwater drawdown and the scale of the affected area was too large, exceptionally, the Siphon Drainage line was placed in the middle of the instable slope, below the road (Fig. 6). The drainage network was created by a single line of a total length of $130 \mathrm{~m}$ by 26 vertical Siphon Drains equipped with protective manholes ( 800 $\mathrm{mm}$ in diameter) with a spacing of $4 \mathrm{~m}$. The drainage trench (for construction of the manholes, placing a collector at $\varnothing 200 \mathrm{~mm}$ for siphon tubes and a perforated collector at $\varnothing 150 \mathrm{~mm}$ for surface water) was up to $2.5 \mathrm{~m}$ deep (to realize the 


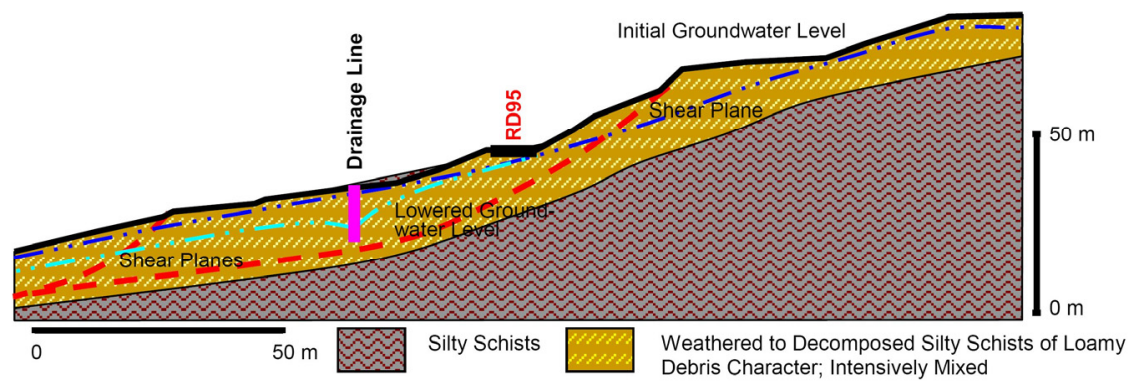

Figure 5: Cross-section of the affected slope at Aigueblanche.
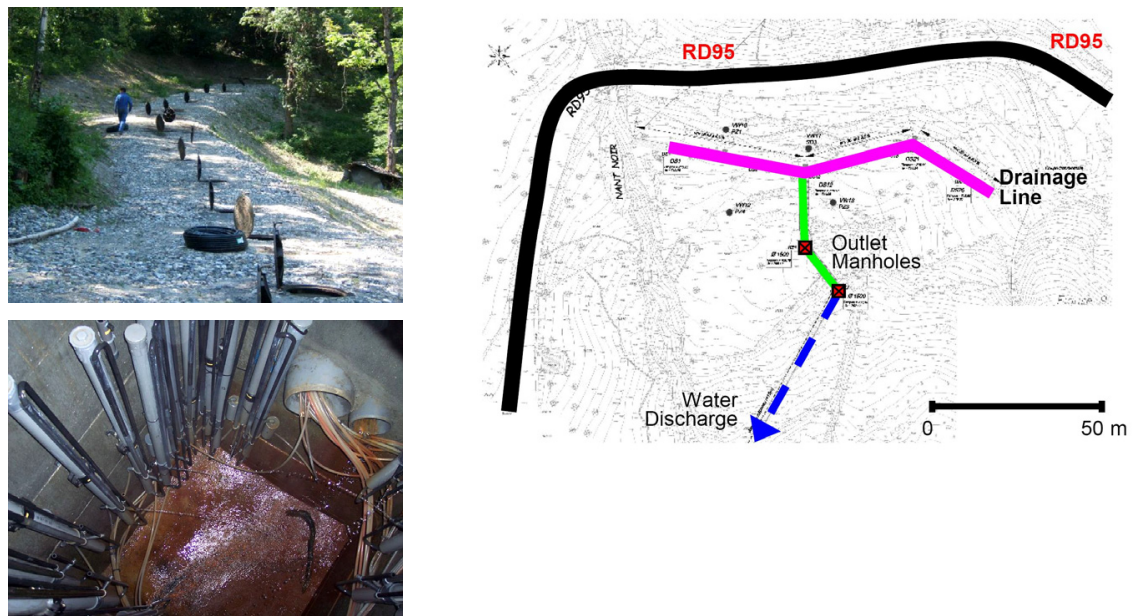

Figure 6: Scheme of the Siphon Drainage System at Aigueblanche.

drawdown as deep down as possible). After construction and backfilling of the trench, the boreholes were drilled up to $15 \mathrm{~m}$ beneath the surface. Two outlet manholes were executed in the slope below the drainage line. The outlet manholes were constructed from prefabricated rectangle concrete units of a $1500 \mathrm{~mm}$. The outlet manholes were connected to the drainage line by the same type of trench as the trench between the drains, including a $\varnothing 200 \mathrm{~mm}$ ducting pipe (collector) for siphon tubes and a $\varnothing 150 \mathrm{~mm}$ perforated collector for surface water. The drains were constructed and equipped as standard opened piezometers. The diameter of drilling was $250 \mathrm{~mm}$. A perforated plastic pipe $\varnothing 110 / 114 \mathrm{~mm}$ was inserted into the boreholes and the space between the borehole wall and the screen was filled with gravel of grading 2-4 mm. The water collected by the drains is sucked out of the wells by the natural siphon principle through $10 / 12 \mathrm{~mm}$ diameter plastic siphon pipes inserted into each well. After the lower situated outlet manhole, the collected ground and surface water was directed by gravity downstream, to an opened concrete ditch. A system of continual groundwater monitoring by piezometers was established. 
After the system was put in function, the groundwater level in each well was lowered to $10-12 \mathrm{~m}$ below the surface. The maximal registered flow for one single drain was $1.7 \mathrm{l} / \mathrm{min}$. For reasons of extreme water inflows into some drains, the capacity was increased at these places by additional siphon tubes inserted into the wells or by changing the diameter of the tubes. By doing this, the maximal managed water flow was increased to $15 \mathrm{l} / \mathrm{min}$. In 2010 , the system had been in operation for four years without any defects. Regular periodical maintenance of the drainage is carried out. No problems with stability of the area occur anymore.

\section{$5 \quad$ RD104 - Saint Priest}

The road in the vicinity of Saint Priest was deformed due to general slope instability caused by a high water table (Fig. 7). A section of approximately $100 \mathrm{~m}$ of the state road RD104 was in danger if nothing was done.

The bedrock at the site is characterized by marls of different degrees of alteration and different degrees of compaction. The marls are alternating with limestones. It is though that the rockmass is slightly jointed. Quaternary deposits are developed as heterogenous debris, the thickness of which increases uphill from $0 \mathrm{~m}$ below the road embankment to $5 \mathrm{~m}$ in the slope above the road. This was caused by earthworks during the road construction. The upper groundwater level should have been lowered and was initially following the boundary between the debris and the marls. It was also observed to be very shallow in the marls below the road embankment. The upper water level was oscillating strongly according to precipitation. The lower groundwater level was explored in the marl formations, but it was thought not to have an influence on the stability problems.

In order to guarantee the water table lowering, the Siphon Drains method was selected as the most convenient for permanent water drawdown without electricity consumption. By using vertical wells, the water could have been easily lowered up to the depths required by the geotechnical designer in order to improve the general stability of the slope (Fig. 8).

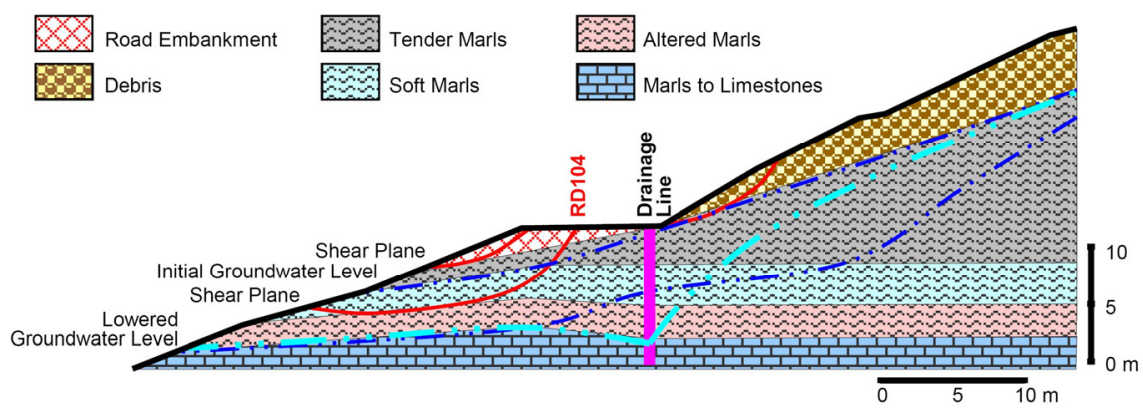

Figure 7: Cross-section of the affected slope at Saint Priest. 
The drainage network was arranged in a single line containing 37 drains. The line was placed just next to the road. The standard arrangement of the Siphon Drainage system was kept at this site. A trench of $1.5 \mathrm{~m}$ minimum depth in which to place all necessary ducting, as well as to protect the equipment of the Siphon Drainage technology against frost action and mechanical destruction, was excavated. To realize the drawdown as deep down as possible, the trench was excavated up to $2 \mathrm{~m}$ depth. Protective drainage manholes made of concrete prefabricates $\varnothing 800 \mathrm{~mm}$ were placed at the position of each drain. The trench was completely backfilled with gravel. A perforated plastic duct was placed at the bottom to be used as a surface drain. The wells were drilled at $\varnothing 250 \mathrm{~mm}$ from the top of the manholes after backfilling the trench. The drains are $13.5 \mathrm{~m}$ deep. The distances between the drains are $3 \mathrm{~m}$. The wells were equipped as standard opened piezometers. A perforated plastic pipe of $\varnothing 110 / 114 \mathrm{~mm}$ was inserted into the boreholes and the space between the borehole and the screen was filled with filtrating gravel of 2-4 mm. An air-lift to clean the wells was applied.

The collected groundwater was directed through siphon pipes (one for each drain) in two evacuation lines. The water collected by the drains is sucked out of the wells by the natural siphon principle through $10 / 12 \mathrm{~mm}$ diameter plastic siphon pipes inserted into each well and pulled through the burned ducting pipes between neighbouring manholes to two crosspoint manholes and then to four downstream placed common outlet manholes. Flushing systems for each drain were installed in the outlet manholes. The siphon tubes were primed by water

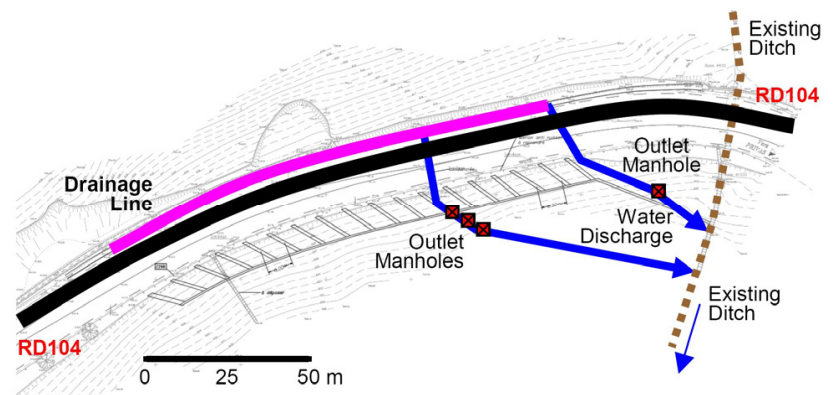

Figure 8: $\quad$ Scheme of the Siphon Drainage System at Saint Priest.
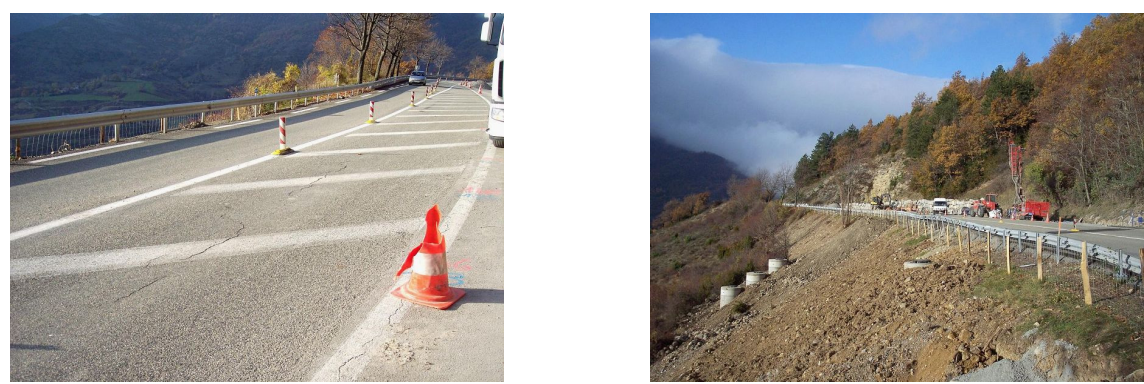

Figure 9: Deformations of the road and view at the Saint Priest site. 
under pressure and the outlet endings of the siphon pipes were connected to relevant flushing systems. The final water evacuation was realized to an existent opened ditch.

A system of continual groundwater monitoring was established by means of 14 vibrating wire piezometers placed into the same wells. Telemetry was set up so the data could be downloaded, checked and processed anytime in the office and provided online to the client. After the system was put in function, the groundwater level in each well was lowered to $9-13 \mathrm{~m}$ below the surface. At the moment of preparing this article (soon after installation of the system), no information about water flows were known. Regular periodical maintenance of the drainage is carried out.

\section{TGV Corridor - Chabrillan}

The "Chabrillan" is a major cutting excavated in 1998 on the TGV high speed train link in France. It is located 530.300,20 km south of Valence. The cut is $1000 \mathrm{~m}$ long, with a maximum depth $35 \mathrm{~m}$. In summer 2000, minor deformations on the access road were noticed. Later on, larger scale movements of a few centimetres in width resulted in a narrow fissure on the slope above the road. By the end of 2000, the fissure developed into a major feature of $30 \mathrm{~m}$ in length. It was suggested that movements and slope failures could affect the cutting and the train corridor. In 2001, the maximum recorded lateral ground movement reached about $1 \mathrm{~mm}$ /day towards the rail line and a total volume of $1.200000 \mathrm{~m}^{3}$ was in movement along two shear planes that were identified at the site.

The geology comprises molasse deposits principally formed by sandstones and fresh water limestones with the presence of karstic features and interlayers of plastic clayey marls (Fig. 10). Alpine tectonics is apparent by the presence of thrust planes inclined at $15-20^{\circ}$ towards the cutting. Groundwater was observed at two levels, generally at depths of $20 \mathrm{~m}$ and $33 \mathrm{~m}$ below the crest of the cutting. Inclinometer records confirmed the presence of two main levels of ground movement at $19 \mathrm{~m}$ and $30 \mathrm{~m}$. The total volume of the material in movement was indicated as $1.200 .000 \mathrm{~m}^{3}$. It was proposed to make an unloading cut and to excavate $600.000 \mathrm{~m}^{3}$ of material in the slope behind the railway cutting to relieve the disturbing forces driving the slope instability. After performance of the excavation, the groundwater level was monitored in 2001-2005 and observed at $0-8 \mathrm{~m}$ beneath the base of the cut. In 2002, new movements were registered.

To control the groundwater level and to reduce the deformations, several dewatering schemes were considered. A $10 \mathrm{~m}$ deep trench for a length of $150 \mathrm{~m}$ was designed to be excavated from the base of the unloading cut. This solution suffered from a number of limitations: in particular, the trench might increase the risk of new shear failures. Subhorizontal wells were rejected due to considerable length and minimal efficiency due to generally low permeability and complex aquifers. To achieve the required drawdown, a deep drainage system was assumed as the most appropriate approach. Immerged pumps were not selected due to their poor efficiency at low permeabilities and inflows and for high energy requirements. The limitations of the gravity Siphon Drainage system lay in the 


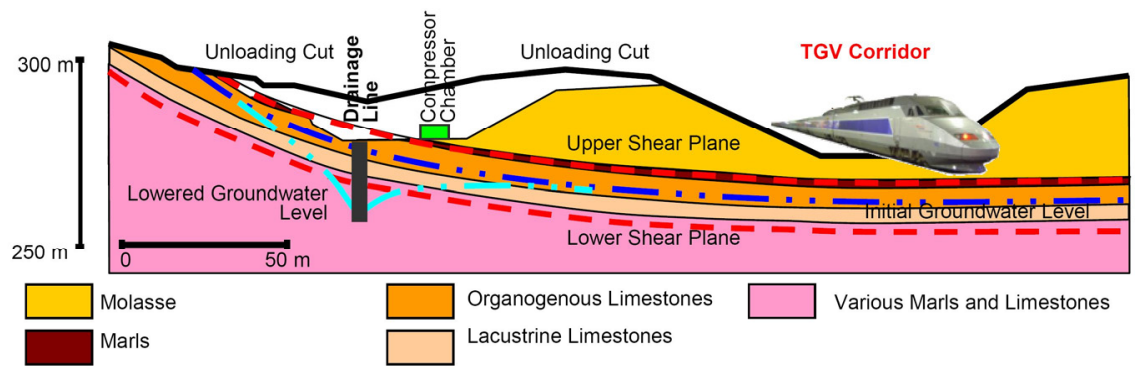

Figure 10: Cross-section of the affected slope at Chabrillan.
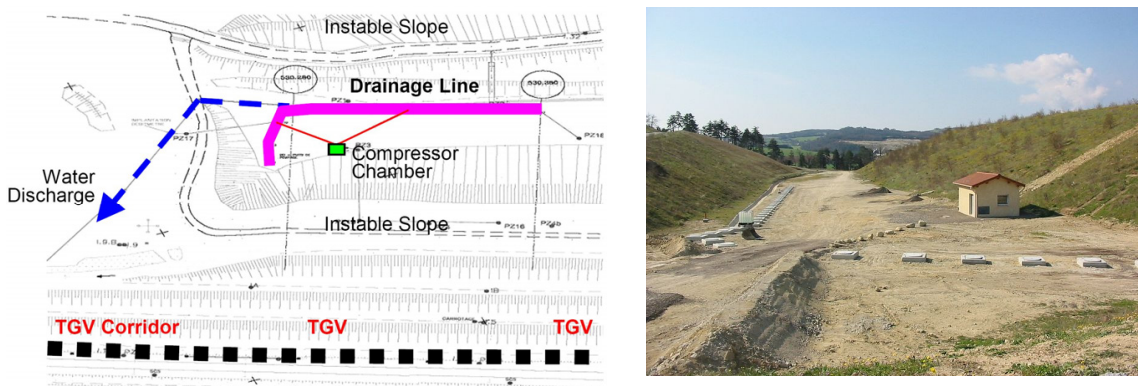

Figure 11: Scheme of the Electropneumatic Drainage System at Chabrillan.

plain gradient of the ground surface. Based on the slide characteristics, the site morphology, the required drawdown and the total construction, operation and service expenses of the drainage, a scheme by Electropneumatic Drains was selected as the most effective solution.

The design comprised 47 wells arranged in a $150 \mathrm{~m}$ long line (Fig. 11). The wells were bored at $200 \mathrm{~mm}$ diameter into 12-20 m depth and equipped with electropneumatic pumps. A slotted PVC casing of $103 \mathrm{~mm}$ internal diameter was installed to full depth. The annulus was filled with a fine graded gravel filter of 2-4 mm size. Each drain was equipped with a protective manhole of $1.5 \mathrm{~m}$ depth. All tubings and cables were led from wells to the compressor chamber where the compressors $(2 \times 30 \mathrm{~kW}$, one as a back-up), the control panel and the accessories were installed. The chamber was designed as a simple brick house $(4 \times 6 \mathrm{~m})$. A comprehensive system of instrumentation and monitoring was established. The monitoring comprised continual water level measuring, inclinometry and water flow observations. An alarms system by GSM was set-up for alerts in the case of high water level or any disconnection problems. Internet Explorer was chosen as the interface for the drainage system operation and monitoring results online checking.

The groundwater was lowered from the original $0-8 \mathrm{~m}$ to $11-15 \mathrm{~m}$ beneath the base of the unloading excavation. The drawdown and drainage efficiency comply with the requirements. The maximal total flow rates recorded reached 8 $280 \mathrm{l} / \mathrm{min}(0.2-6 \mathrm{l} / \mathrm{min}$ per drain). The actual moderate flow rate alternates at around $0.2 \mathrm{l} / \mathrm{min}$ per well $(8 \mathrm{l} / \mathrm{min}$ in total). In 2010 , the system had been in 
operation for four years without any defects. Regular periodical maintenance ofthe drainage is carried out. No new slope deformations were registered after start-up of the system. In 2010, a special French price "Ivor" for quality and for innovative solution was given to Electropneumatic Drainage at this site.

\section{Conclusions}

Corridors of roads, highways or railways are frequently surrounded by slopes natural hills or artificial cuts. The presence of groundwater in the slopes is one of the most negative factors that can affect the stability and functionality of the infrastructure tracks. Groundwater lowering is one of the ways to stabilize slope movements by improving the properties of soils and rocks and avoiding or reducing the risk of new deformations and damages of the structures. The method of groundwater lowering is very important. In this article, two innovative alternatives of dewatering by systems of deep vertical wells were introduced.

Since many of the stability problems of roads appear in non-urbanized areas without good access for a source of power, the gravity method of Siphon Drainage seems to be an ideal and very effective solution for long-term permanent groundwater lowering without any need for electricity for water pumping. In the case that the water table should be reduced by up to 8-12 $\mathrm{m}$ beneath the surface and the expected water inflows are around $2-151 / \mathrm{min}$ per well, this method provides a reliable solution.

The method of Electropneumatic Drains represents a flexible system of dewatering which does not require any specific morphology of the treated sites. It is suitable for urgent, emergency and even temporary solutions of deeper seated problems (up to $60 \mathrm{~m}$ depth). In the case that the groundwater level is supposed to be reduced in cycles (continuous pumping is not expected), the expenses for electricity and maintenance of the equipment can be saved by use of a single conventional compressor (10-50 kW/ 10-15 bars for 20-150 wells up to $60 \mathrm{~m}$ depth) instead of many submersible pumps of the same rated power input. A huge amount of water per well (up to $70 \mathrm{l} / \mathrm{min}$ ) can be managed to be pumped.

\section{References}

[1] Bomont, S., Mrvík, O., Back Experience from Two Cases of Stabilization of Coastal Landslides by Innovative Deep Drainage Systems, Proc. of the 11th Baltic Sea Geotechnical Conference, Vol. 1, pp. 19-26, 2008.

[2] Bomont, S., Mrvík, O., Back Experience of Innovative Deep Drainage Systems for Slopes Dewatering and Landslides Stabilizations, Geoinzynieria - drogi, mosty, tunele, 04/2008 (19), pp. 60-65, ISSN 1895-0426, 2008.

[3] Mrvík, O., Bomont, S., Application of Innovative Method of Deep Drainage by Siphon Drains for Stabilization of Slopes of Former Opened-Cast Brown Coal Mine "Most - Lezaky" (Czech Republic), Geotechnika, 2/2009, pp. 20-25, ISSN 1211-913X, 2009. 